\title{
Pattern of Electrolyte Imbalance in Hospitalized Diabetic Patients: Experience in a Tertiary Care Hospital
}

\author{
HAQUE HF ${ }^{\mathrm{a}}$, AMIN MG ${ }^{\mathrm{b}}$, UDDIN KN ${ }^{\mathrm{c}}$, AHMED JU ${ }^{\mathrm{d}}$, AHMED AKMS ${ }^{\mathrm{e}}$, RAHIM MA ${ }^{\mathrm{d}}$, DEWAN Pa, \\ SAMAD T ${ }^{\mathrm{a}}$
}

\begin{abstract}
Introduction: Bangladesh Institute of Research and Rehabilitation in Diabetes, Endocrine and Metabolic Disorders (BIRDEM) is the largest specialized hospital in Bangladesh for care of diabetic patients. Here, most of the hospitalized patients are diabetic, having many complications of diabetes mellitus and other co-morbidities. They often require multiple drugs for treatment. Diabetes mellitus itself, its complications and various medicationsall are related to development of electrolyte imbalance, which are often under-estimated or remain un-diagnosed.

Objectives: The Objectives of this study were to see the pattern of electrolyte imbalance in hospitalized diabetic patients and to find out the precipitating causes behind them.

Methods: This cross-sectional study was done in the Department of Internal Medicine, BIRDEM in 2008. Data were collected by random sampling from the first 100 adult diabetic patients with electrolyte imbalance, irrespective of their cause of admission.
\end{abstract}

Results: Total number of patients were 100, male were 74 and female were 26 (M:F ratio 2.85: 1). Mean age was 60.18 years with standard deviation of \pm 12.15 years (Range 3890 years). Among the patients, the mean duration of the diabetes mellitus was 10.96 years with standard deviation \pm 8.05 years. Majority (83\%) of the patients were on insulin,

a. Dr. Hasna Fahmima Haque, FCPS (Medicine), Dr. Pratik Dewan, MD(Medicine), Dr. Tabassum Samad, FCPS (Medicine), Senior Medical Officer, BIRDEM General Hospital, Shahbag, Dhaka.

b. Dr. Mohammad Gaffar Amin, MD (Cardiology), Registrar, Cardiology, Dhaka Medical College Hospital.

c. Prof. Khwaja Nazim Uddin, FCPS (Medicine), FRCP, FACP. Professor of Medicine, Ibrahim Medical College and BIRDEM General Hospital, Shahbag, Dhaka.

d. Dr. Jamal Uddin Ahmed, FCPS (Medicine), Dr. Muhammad Abdur Rahim, FCPS (Medicine), Registrar, Internal Medicine, Ibrahim Medical College and BIRDEM General Hospital, Shahbag, Dhaka.

e. Dr. AKM Shaheen Ahmed, FCPS (Medicine), Assistant Professor, Internal Medicine, Ibrahim Medical College and BIRDEM General Hospital, Shahbag, Dhaka.

Address of Correspondance: Dr. Hasna Fahmima Haque, FCPS (Medicine), Senior Medical Officer, Department of Internal Medicine, Ibrahim Medical College and BIRDEM General Hospital, Shahbag, Dhaka. E-mail: drfahmimahaque@gmail.com.

Received: October 26, 2011

Accepted: December 22, 2011
$22 \%$ were on oral anti-diabetic agents and $6 \%$ were on medical nutrition therapy. Among the co-morbidities, hypertention was the most prevalent (61\%), followed by ischaemic heart disease (24\%), chronic kidney disease (21\%), dyslipidaemia (8\%) and fatty liver (4\%). Diabetic peripheral neuropathy was present in $41 \%$ cases, nephropathy in $13 \%$ cases and retinopathy in $12 \%$ cases. Over all 78\% (100 patients had electrolyte imbalance out of 128 patients) of patients had some sort of electrolyte imbalance, irrespective of cause of admission. Hyponatraemia was the most common electrolyte imbalance in this study (80\%), followed by hypomagnaesemia (38\%), hypokalaemia (36\%) and hyperkalaemia (14\%). In 11\% cases there were hyponatraemia, hypokalaemia and hypomagnaesemia. Regarding the precipitating factors, vomiting was most common (51\%). In $28 \%$ cases electrolyte imbalance was precipitated by various drugs. Diarrhea and renal failure were responsible in a minority of cases. In 4\% cases no cause could be identified. No death occurred.

Conclusion: From this cross-sectional study it can be concluded that, electrolyte imbalance is common in hospitalized diabetic patients. Serum electrolytes should be checked routinely in hospitalized diabetic patients irrespective of their purpose of admission.

Key words: Dibetes Mellitus, electrolyte imbalance

(Birdem Med J 2012; 2(1): 14-18)

\section{Introduction}

Diabetes mellitus (DM) is rapidly emerging as an important cause of mortality and morbidity in developing countries. ${ }^{1}$ It is an established risk factor for coronary heart disease (CHD), stroke and end-stage renal disease (ESRD). Diabetic nephropathy is one of the complications of diabetes mellitus, which ultimately leads to renal failure and renal failure is a cause of electrolyte imbalance among hospitalized diabetic patients; other causes are diarrhea, vomiting, diuretic use and chronic laxative use. The most common electrolyte imbalance is hyponatraemia, others are hypokalaemia, hypomagnesaemia and hyperkalaemia.

Hyponatraemia, defined as a plasma sodium concentration $<130 \mathrm{mmol} / \mathrm{L}$, usually reflect a hypotonic state. However, plasma osmolality may be normal or increased in some cases of hyponatraemia. Hypertonic 
hyponatraemia is usually due to hyperglycemia. Relative insulin deficiency causes myocyte to become impermeable to glucose. Therefore, during poorly controlled diabetes mellitus, glucose is an effective osmole and draws water from muscle cells resulting in hyponatraemia. Isotonic hyponatraemia may occur in conditions like hyperlipidemia and hyperproteinemia. In general, hypotonic hyponatraemia occurs due either to a primary $\mathrm{Na}^{+}$loss (secondary water gain) like sweating, burns, gastrointestinal loss: vomiting, diarrhea; renal loss: diuretics, hypoaldosteronism, saltwasting nephropathy; or due to a primary water gain (secondary $\mathrm{Na}^{+}$loss) like SIADH, hypothyroidism, primary polydipsia; or due to a primary $\mathrm{Na}^{+}$gain (exceeded by secondary water gain) like heart failure, hepatic cirrhosis, nephritic syndrome. It is important to note that diuretic-induced hyponatraemia is almost always due to thiazide diuretics and cerebral salt wasting after neurosurgery are also the cause of hyponatraemia. ${ }^{2}$ Hypernatraemia can occur in hyperglycaemic hyperosmolar state.

Potassium is the principal intracellular cation and maintenance of the distribution of potassium between the intracellular and the extracellular compartments relies on several homeostatic mechanisms; when these mechanisms are perturbed, hypokalemia or hyperkalemia may occur. ${ }^{3}$ Hypokalemia, defined as a plasma $\mathrm{K}^{+}$concentration $<3.5 \mathrm{mmol} / \mathrm{L}$, may result from one or more of the followings: decreased net intake like starvation; shift into cells like metabolic alkalosis, insulin, $\hat{a}_{2}$ Adrenergic agonist, total parenteral nutrition; and increased net loss like diarrhea, sweating, renal loss: diuretics, primary and secondary hyperaldosteronism. Diminished intake is seldom the sole cause of $\mathrm{K}^{+}$ depletion since urinary excretion can be effectively decreased to $<15 \mathrm{mmol} /$ day as a result of net $\mathrm{K}^{+}$ reabsorption in the distal nephron. However, dietary $\mathrm{K}^{+}$ restriction may exacerbate the hypokalemia secondary to increased gastrointestinal or renal loss. ${ }^{4}$

Hyperkalemia, defined as a plasma $\mathrm{K}^{+}$concentration $>5.3 \mathrm{mmol} / \mathrm{L}$, occurs as a result of either $\mathrm{K}^{+}$release from cells or decreased renal loss. Increased $\mathrm{K}^{+}$intake is rarely the sole cause of hyperkalemia since the phenomenon of potassium adaptation ensures rapid $\mathrm{K}^{+}$ excretion in response to increase in dietary consumption. Iatrogenic hyperkalemia may result from overzealous parenteral $\mathrm{K}^{+}$replacement or in patients with renal insufficiency. Metabolic acidosis, with the exception of those due to the accumulation of organic anions, can be associated with mild hyperkalemia resulting from intracellular buffering of $\mathrm{H}^{+}$. Insulin deficiency and hypertonicity (e.g., hyperglycemia) promote $\mathrm{K}^{+}$shift from the ICF to the ECF. The severity of exerciseinduced hyperkalemia is related to the degree of exertion. It is due to release of $\mathrm{K}^{+}$from muscles and is usually rapidly reversible. Severe digitalis toxicity and treatment with beta blockers may contribute to the elevation in plasma $\mathrm{K}^{+}$concentration. Other drugs like angiotensin receptor inhibitors (ACE inhibitors), angiotensin receptor blocker (ARBs) and spironolactone are often responsible for hyperkalaemia. Pseudohyperkalemia represents an artificially elevated plasma $\mathrm{K}^{+}$concentration due to $\mathrm{K}^{+}$movement out of cells immediately prior to or following venepuncture. Contributing factors include prolonged use of a tourniquet with or without repeated fist clenching, hemolysis, and marked leukocytosis or thrombocytosis. Intravascular hemolysis, tumor lysis syndrome, and rhabdomyolysis all lead to $\mathrm{K}^{+}$release from cells as a result of tissue breakdown. ${ }^{4}$

Magnesium is the major intracellular divalent cation that forms a key complex with ATP and is an important cofactor for a wide range of enzymes, transporters, and nucleic acids required for normal cellular function, replication, and energy metabolism. The concentration of magnesium in serum is closely regulated within the range of $0.7-1.0 \mathrm{mmol} / \mathrm{L}(1.5-2.0 \mathrm{meq} / \mathrm{L} ; 1.7-2.4 \mathrm{mg} /$ dL). ${ }^{4}$

Magnesium deficit is associated with several acute and chronic illnesses, of major concern is the association of hypomagnesaemia with cardiovascular problems, such as myocardial infarction, hypertension and congestive heart failure. In addition, evidence is mounting regarding the relationship between Type 2 Diabetes Mellitus, and magnesium deficit. Hypomagnesaemia can result from intestinal malabsorption; protracted vomiting, diarrhea, or intestinal drainage; defective renal tubular magnesium reabsorption; or rapid shift of magnesium from the ECF into cells, bone, or third spaces. Dietary magnesium deficiency is unlikely except possibly in the setting of alcoholism. $^{5}$ 


\section{Materials and methods}

This Cross-sectional study was carried out in the Department of Internal Medicine of BIRDEM Hospital, Dhaka with an aim to see the pattern of electrolyte imbalance in hospitalized diabetic patients and to identify the etiological factors. The study was done in the year 2008. Data were collected by random sampling method, through a semi-structured data collection sheet. The first 100 adult diabetic patients who were found to have electrolyte imbalance, in general medical ward were included in the study. Patients with advanced renal failure (serum creatinine more than $5 \mathrm{mg} / \mathrm{dl}$ ), those with normal serum electrolytes, those taking electrolyte supplements and those unwilling to be included in the study were excluded. All the data were compiled and appropriate statistical analyses were done.

\section{Results}

Total number of patients were 100 , male were 74 , female were 26 , the male and female ratio was: $2.85: 1$. The mean age was 60.18 years with $\mathrm{SD} \pm 12.15$ years, ranging from 38 to 90 years. Among them 13 (13\%) were of below 45 years, 24 (24\%) were of $45-54$ years age group, 34 (34\%) were of 55-64 years age group, 16 $(16 \%)$ were of $65-74$ years age group and $13(13 \%)$ were of $>75$ years age group. Among the study subjects, the mean duration of DM was 10.96 years with $\mathrm{SD} \pm$ 8.05. Regarding treatment, $83(83 \%)$ of the study subjects were on insulin therapy, $22(22 \%)$ were on oral hypoglycemic agents and $6(6 \%)$ were on medical nutrition therapy.

Among the 100 study subjects, 61 (61\%) had hypertension (HTN), 24 (24\%) had ischemic heart diseases (IHD), 21 (21\%) had renal diseases, 8 (8\%) had dyslipidemia and 4 (4\%) had liver diseases (Figure 1). Of the 100 study subjects, 41 (41\%) had diabetic nephropathy, $13(13 \%)$ had diabetic neuropathy and 12 $(12 \%)$ had diabetic retinopathy (Table I).

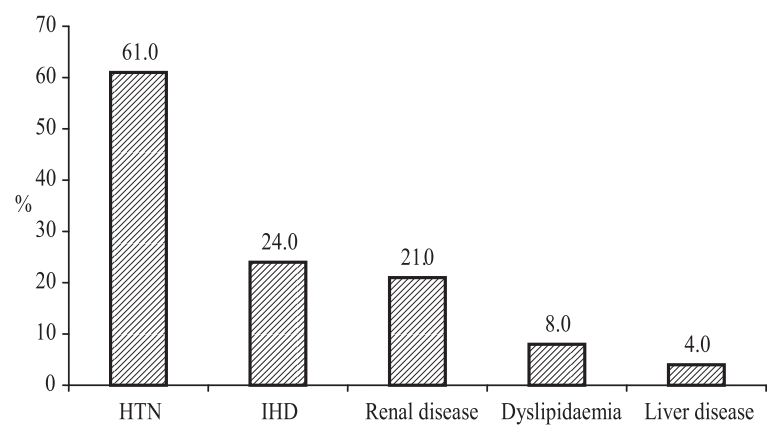

Fig.-1: Co-morbidities of study subjects
Table-I

\begin{tabular}{|c|c|c|}
\hline \multicolumn{3}{|c|}{$\begin{array}{l}\text { Distribution of the study subjects by } \\
\text { complications of DM }\end{array}$} \\
\hline Complications of DM & Frequency & Percen \\
\hline Nephropathy & 41 & 41.0 \\
\hline Neuropathy & 13 & 13.0 \\
\hline Retinopathy & 12 & 12.0 \\
\hline
\end{tabular}

Among the 100 study subjects, 20 (20\%) had normal sodium level and $80(80 \%)$ had hyponatremia (Table II). The mean sodium level was $127.47 \mathrm{mmol} / \mathrm{L}$ with $\mathrm{SD} \pm 8.11 \mathrm{ranging}$ from $110.0 \mathrm{mmol} / \mathrm{L}$ to $144.0 \mathrm{~mol} / \mathrm{L}$. Of the 100 study subjects, $36(36 \%)$ had hypokalemia, $50(50 \%)$ had normal potassium level and $14(14 \%)$ had hyperkalemia (Table II). The mean potassium level was $3.98 \mathrm{mmol} / \mathrm{L}$ with $\mathrm{SD} \pm 1.13$ ranging from 1.80 $\mathrm{mmol} / \mathrm{L}$ to $7.10 \mathrm{mmol} / \mathrm{L}$. Among the 100 study subjects, $38(38 \%)$ had hypomagnesemia and $62(62 \%)$ had normal magnesium level. The mean magnesium level was $0.76 \mathrm{mmol} / \mathrm{L}$ with $\mathrm{SD} \pm 0.21$ ranging from 0.40 $\mathrm{mmol} / \mathrm{L}$ to $1.20 \mathrm{mmol} / \mathrm{L}$ (Table II).

Table II

Distribution of study subjects by plasma sodium, potassium and magnesium level

\begin{tabular}{lcc}
$\mathrm{Na}^{+}$ & Frequency & Percent \\
\hline Normal $(>130)$ & 20 & 20.0 \\
Hyponatremia $(<130)$ & 80 & 80.0 \\
Total & 100 & 100 \\
Mean \pm SD (Range) & $127.47 \pm 8.11$ & \\
& $(110.0-144.0)$ & \\
\hline
\end{tabular}

\begin{tabular}{lcc}
\hline $\mathrm{K}^{+}$ & Frequency & Percent \\
\hline $\begin{array}{l}\text { Hypokalaemia } \\
(<3.5 \mathrm{mmol} / \mathrm{L})\end{array}$ & 36 & 36.0 \\
$\begin{array}{l}\text { Norma } \\
\text { Hyperkalaemia }\end{array}$ & 150 & 50.0 \\
$(>5.2 \mathrm{mmol} / \mathrm{L})$ & & \\
Total & 141 & 4.0 \\
Mean \pm SD (Range) & $3.98 \pm 1.13$ & 100.0 \\
& $(1.80-7.10)$ & \\
\hline Mg & & \\
\hline Hypomagnesaemia & Frequency & Percent \\
Normal & 38 & 38.0 \\
Total & 62 & 62.0 \\
Mean \pm SD (Range) & $0.76 \pm 0.21$ & 100.0 \\
& $(0.40-1.20)$ & \\
\hline
\end{tabular}


In regard to cause of electrolyte imbalance, $51(51 \%)$ had vomiting, $5(5 \%)$ had diarrhea, $28(28 \%)$ of them were having various drugs, 24 (24\%) had renal failure, other causes were found in 2 cases and 4 (4\%) had unknown causes (Figure 2).

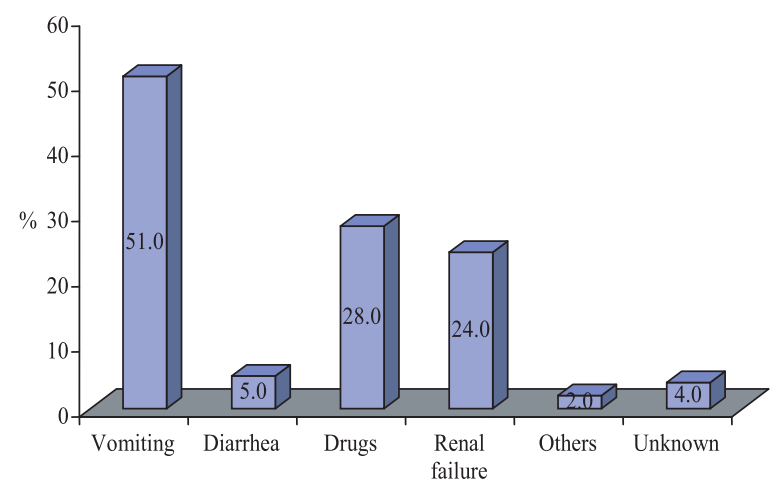

Fig.-2: Distribution of patients by the cause electrolyte imbalance

\section{Discussion}

In this cross-sectional study, it was found that $78 \%$ of the hospitalized diabetic patients had electrolyte imbalance, hyponatraemia being the most common $(80 \%)$. Other studies have also shown that hyponatraemia is common in hospitalized patients and increase mortality. ${ }^{6,7,8}$ Hyponatraemia can develop in hospital and it is preventable. ${ }^{9}$ Drug induced hyponatraemia is common in elderly females. ${ }^{10}$ Another study have also shown that hyponatraemia increases mortality irrespective of age, sex, cause and co-existing hypokalaemia. ${ }^{11}$ No death occurred among our study subjects.

Regarding potassium level, both hypo and hyperkalaemia were found. Hypokalaemia was present in $36(36 \%)$ cases. Thiazide diuretics and vomiting were found as main precipitating causes in this study. In one study, hypokalaemia was found more common with indapamide and one-third of cases had concomitent hyponatraemia. ${ }^{10}$ Mortality of patients with hypokalaemia was found more, particularly in females than those having normal potassium level. ${ }^{12}$ Other studies have also shown that mortality is more in hypokalaemic subjects. ${ }^{13,14}$ Hyperkalaemia was present in $14 \%$ cases in our study. Renal impairment, ACE inhibitors, ARBs and spironolactone were the precipitating factors. In one study renal failure, drugs and hyperglycaemia precipitated hyperkalaemia in $77 \%$,
$63 \%$ and $49 \%$ cases respectively. ${ }^{15}$ It was also stated that hyperkalaemia is associated with DM but the exact prevalence is lacking. ${ }^{16}$ In our study 2 cases had ECG changes, but no fatality occurred.

Serum magnesium level is often not routinely measured and hypomagnaesemia was found in $38 \%$ cases. In one study frequency was much higher, $63.3 \% .{ }^{17}$ In another study, prevalence was $42 \%$ in malnutrition related diabetes mellitus patients. ${ }^{18}$

\section{Conclusion}

From this study, it was found that hyponatraemia, hypokalaemia and hypomagnaesemia were common electrolyte imbalance in hospitalized diabetic patients. Prevalence of hyperkalaemia was less common. Vomiting, diarrhea, various medications and renal impairment were the most common precipitating factors. The current study unravels the need for measuring serum electrolytes in hospitalized diabetic patients routinely and at regular intervals, particularly those having diabetic complications, other co-morbidities and those having polypharmacy. As it was a single center-based study and the study population was limited, larger multicentered studies are needed in future for policy adoption and implementation to reduce the burden of an important non-communicable disease like DM, as well as its associations and complications.

\section{References}

1. Zaman M M, Choudhury S R, Ahmed J, Numan S M, Islam S $\mathrm{M}$, and Yoshiike N; Nonbiochemical risk factors for cardiovascular disease in general clinic-based rural population of Bangladesh. Journal of Epidemiology 2004; 14: 63-68.

2. Gary G.Singer. Electrolyte imbalance. In : Braunwald E, Fauci A, Kasper D, Hauser SL, Longo DL and Jameson JL, editors. Harrison's Principles of Internal Medicine. $16^{\text {th }}$ ed. New York: McGraw-Hill. 2005: 255.

3. Kimberley J. Evans, Arthur Greenberg. Hyperkalaemia: A Review. Journal of Intensive Care Medicine, Vol. 20, No. 5, 272-90 (2005)

4. Gary G.Singer. Electrolyte imbalance. In: Braunwald E, Fauci A, Kasper D, Hauser SL, Longo DL and Jameson JL, editors. Harrison's Principles of internal medicine. $16^{\text {th }}$ ed. New York: McGraw-Hill. 2005: 256-58.

5. Innerarity S. Hpoymagnesemia in acute and chronic illness. Crit Care Nurs Q. 2000 Aug; 23(2): 1-19; quiz 87.

6. Anderson RJ, Chung HM, Kluge R, Schrier RW. Hyponatremia: a prospective analysis of its epidemiology and 
the pathogenetic role of vasopressin. Ann Intern Med. 1985; 102: 164-68.

7. Chung HM, Kluge R, Schrier RW, Anderson RJ. Postoperative hyponatremia. A prospective study. Arch Intern Med. 1986; 146: $333-36$.

8. ArieffAI. Acid-base, electrolyte, and metabolic abnormalities. In: Parrillo JE, Dellinger RP, editor. Critical Care Medicine: Principles of Diagnosis and Management in the Adult. 2. St. Louis: Mosby; 2002. pp. 1169-1203.

9. Adrogue HJ, Madias NE. Hyponatremia. NEngl J Med. 2000; 342: 1581-89.

10. Michael D Chapman, Ross Hanrahan, John McEwen and John E Marley. Hyponatraemia and hypokalaemia due to indapamide. The Medical Journal of Australia. 2002; 176 (5): 219-21.

11. Lee CT; Guo HR; Chen JB. Hyponatremia in the emergency department. Am J Emerg Med - 01-MAY-2000; 18(3): 26488
12. Lawson DH, Henry DA, Lowe JM, Gray JM, Morgan HG. Severe hypokalemia in hospitalized patients. Arch Intern Med. 1979 Sep; 139(9): 978-80.

13. Ora Paltiel. Management of Severe Hypokalemia in Hospitalized Patients. Arch Intern Med. 2001; 161: 1089-95.

14. Paice BJ. Record linkage study of hypokalaemia in hospitalized patients. Postgraduate Medical Journal 1986; 62:187-91.

15. Christopher G. Acker, John P. Johnson, Paul M. Palevsky, Arthur Greenberg. Hyperkalemia in Hospitalized Patients. Arch Intern Med. 1998; 158:917-24.

16. Jarman PR, Kehely AM, Mather HM. Hyperkalaemia in diabetes: prevalence and associations. Postgrad Med J. 1995 Sep; 71(839):551-52.

17. Haque WMM. Frequency of hypomagnesaemia in hospitalized diabetic hypokalemic patients. Dissertation for FCPS examination of BCPS, 2004.

18. Khan LA. Serum and urinary magnesium in young diabetic subjects in Bangladesh. Am J Clin Nutr, 1999; 69:70-73. 